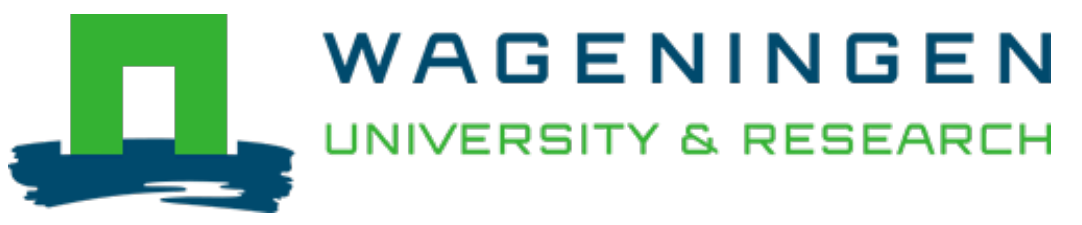

\title{
Association of Habitual Preoperative Dietary Fiber Intake with Complications after Colorectal Cancer Surgery
}

\author{
JAMA Surgery \\ Kok, Dieuwertje E.; Arron, Melissa N.N.; Huibregtse, Tess; Kruyt, Flip M.; Bac, Dirk Jan et al \\ https://doi.org/10.1001/jamasurg.2021.2311
}

This publication is made publicly available in the institutional repository of Wageningen University and Research, under the terms of article $25 \mathrm{fa}$ of the Dutch Copyright Act, also known as the Amendment Taverne. This has been done with explicit consent by the author.

Article 25 fa states that the author of a short scientific work funded either wholly or partially by Dutch public funds is entitled to make that work publicly available for no consideration following a reasonable period of time after the work was first published, provided that clear reference is made to the source of the first publication of the work.

This publication is distributed under The Association of Universities in the Netherlands (VSNU) 'Article $25 \mathrm{fa}$ implementation' project. In this project research outputs of researchers employed by Dutch Universities that comply with the legal requirements of Article $25 \mathrm{fa}$ of the Dutch Copyright Act are distributed online and free of cost or other barriers in institutional repositories. Research outputs are distributed six months after their first online publication in the original published version and with proper attribution to the source of the original publication.

You are permitted to download and use the publication for personal purposes. All rights remain with the author(s) and / or copyright owner(s) of this work. Any use of the publication or parts of it other than authorised under article $25 \mathrm{fa}$ of the Dutch Copyright act is prohibited. Wageningen University \& Research and the author(s) of this publication shall not be held responsible or liable for any damages resulting from your (re)use of this publication.

For questions regarding the public availability of this publication please contact openscience.library@wur.nl 


\section{Association of Habitual Preoperative Dietary Fiber Intake With Complications After Colorectal Cancer Surgery}

Dieuwertje E. Kok, PhD; Melissa N. N. Arron, MD; Tess Huibregtse, BSc; Flip M. Kruyt, MD; Dirk Jan Bac, MD, PhD; Henk K. van Halteren, MD, PhD; Ewout A. Kouwenhoven, MD, PhD; Evertine Wesselink, MSc; Renate M. Winkels, PhD; Moniek van Zutphen, MSc; Fränzel J. B. van Duijnhoven, PhD; Johannes H. W. de Wilt, MD, PhD; Ellen Kampman, PhD

IMPORTANCE Postoperative complications are associated with increased morbidity and mortality among patients with colorectal cancer. As a modifiable factor associated with gut health, dietary fiber intake is of interest with regard to the risk of complications after surgery for colorectal cancer.

OBJECTIVE To examine the association between preoperative dietary fiber intake and risk of complications after surgery for colorectal cancer.

DESIGN, SETTING, AND PARTICIPANTS This cohort study used data from the Colorectal Longitudinal, Observational Study on Nutritional and Lifestyle Factors (COLON) study, which recruited adult patients with colorectal cancer at any stage at diagnosis from 11 hospitals in the Netherlands between August 2010 and December 2017. The present study included patients with stage I to IV colorectal cancer who underwent elective abdominal surgery. Data were analyzed between December 2019 and September 2020.

EXPOSURES Habitual dietary fiber intake was assessed at diagnosis using a 204-item food frequency questionnaire.

MAIN OUTCOMES AND MEASURES Any complications, surgical complications, and anastomotic leakage occurring during the 30 days after surgery for colorectal cancer. The association between fiber intake and risk of postoperative complications was assessed using logistic regression analyses. Additional analyses stratified by sex, tumor location, and fiber source were performed.

RESULTS Among the 1399 patients included in the analysis, the median age at inclusion was 66 years (interquartile range, 61-72 years) and 896 (64\%) were men. Any complications occurred in 397 patients (28\%), and surgical complications occurred in 235 patients (17\%). Of 1237 patients with an anastomosis, 67 (5\%) experienced anastomotic leakage. Higher dietary fiber intake (per $10 \mathrm{~g}$ per day) was associated with a lower risk of any complications (odds ratio [OR], 0.75; 95\% Cl, 0.62-0.92) and surgical complications (OR, 0.76; 95\% Cl, $0.60-0.97)$, whereas no association with anastomotic leakage was found $(\mathrm{OR}, 0.97 ; 95 \% \mathrm{Cl}$, 0.66-1.43). Among women, higher dietary intake was associated with any complications (OR, 0.64; 95\% Cl, 0.44-0.94), whereas there was no association among men (OR, 0.79; $95 \% \mathrm{Cl}, 0.63-1.01)$. Fiber intake from vegetables (per $1 \mathrm{~g}$ per day) was inversely associated with any (OR, 0.90; 95\% Cl, 0.83-0.99) and surgical (OR, 0.87; 95\% Cl, 0.78-0.97) complications.

CONCLUSIONS AND RELEVANCE In this cohort study, higher habitual dietary fiber intake before surgery was associated with a lower risk of postoperative complications among patients with colorectal cancer. The findings suggest that improving preoperative dietary fiber intake may be considered in future prehabilitation programs for patients undergoing surgery for colorectal cancer

JAMA Surg. doi:10.1001/jamasurg.2021.2311

Published online June 16, 2021.

Author Affiliations: Division of Human Nutrition and Health, Wageningen University \& Research, Wageningen, the Netherlands (Kok, Huibregtse, Wesselink, Winkels, van Zutphen, van Duijnhoven, Kampman); Department of Surgery, Radboud University Medical Center, Nijmegen, the Netherlands (Arron, de Wilt); Department of Surgery, Hospital Gelderse Vallei, Ede, the Netherlands (Kruyt); Department of Gastroenterology and Hepatology, Hospital Gelderse Vallei, Ede, the Netherlands (Bac); Department of Internal Medicine, Admiraal de Ruyter Hospital, Goes, the Netherlands (van Halteren); Department of Surgery, Hospital Group Twente ZGT, Almelo, the Netherlands (Kouwenhoven).

Corresponding Author: Dieuwertje E. Kok, PhD, Division of Human Nutrition and Health, Wageningen University \& Research, PO Box 17, 6700 AA Wageningen, the Netherlands (dieuwertje.kok@ wur.nl). 
S urgery is the indicated treatment modality for most patients with colorectal cancer (CRC) in Western countries. ${ }^{1}$ After tumor resection, severe complications, such as anastomotic leakage, infections, or ileus, occur in $15 \%$ to $50 \%$ of patients. ${ }^{2-5}$ These postoperative complications affect quality of life, length of hospital stay, and readmission and mortality rates. ${ }^{5-9}$ Moreover, complicated recovery after surgery for CRC is associated with increased resource utilization and hospital costs. ${ }^{10}$

Some demographic and clinical characteristics, such as current smoking, male sex, obesity, and comorbidities, have been associated with postoperative complications in patients with CRC. ${ }^{2,5,11-15}$ Emerging evidence suggests that impaired gut health may also be associated with risk of postoperative complications. ${ }^{16,17}$ As a modifiable factor linked to gut health, ${ }^{18,19}$ dietary fiber intake is of specific interest with regard to the risk of complications after gastrointestinal surgery.

Dietary fiber represents oligosaccharides and polysaccharides that resist degradation by human enzymes in the gastrointestinal tract. ${ }^{20}$ Bacterial fermentation of dietary fiber occurs predominantly in the colon and results in production of metabolites, such as short-chain fatty acids (SCFAs), that become available to the host. ${ }^{21}$ In addition to these metabolites, fecal bulking, effect on transit time, and other yet to be confirmed mechanisms have been linked to the positive health effects of dietary fiber. ${ }^{18,21}$ Earlier work in model species showed that inadequate fiber intake resulted in an impaired mucosal barrier and enhanced pathogen susceptibility. ${ }^{22,23}$ Both these phenomena are deemed relevant to the pathogenesis of postoperative complications in patients with CRC. ${ }^{16,24}$

To date, dietary fiber intake has not been extensively considered in multimodal prehabilitation programs, such as the Enhanced Recovery After Surgery guidelines, which mainly focus on prevention of malnutrition through protein and energy intake and specific vitamins and minerals. ${ }^{25,26}$ Therefore, the aim of this study was to examine the association between habitual dietary fiber intake before surgery and the risk of postoperative complications in patients with stage I-IV CRC, with consideration of potential confounding factors.

\section{Methods}

\section{Patients}

This cohort study used data from the Colorectal Longitudinal, Observational Study on Nutritional and Lifestyle Factors (COLON) study. ${ }^{27}$ The COLON study is a prospective cohort study initiated to examine associations of diet and other lifestyle factors with clinical outcomes in patients with CRC. In brief, adult patients (age $\geq 18$ years) with cancer at any stage were recruited directly after diagnosis and before surgery from 11 hospitals in the Netherlands. Patients were not included if they did not speak Dutch, had a history of CRC or bowel resection, or had a diagnosis of inflammatory bowel disease, hereditary CRC, or a mental health condition preventing completion of the study questionnaires. All patients provided written informed consent. The COLON study was reviewed and ap-

\section{Key Points}

Question Is habitual preoperative dietary fiber intake associated with risk of complications after surgery for colorectal cancer?

Findings In this cohort study of 1399 patients with colorectal cancer who underwent surgery, higher habitual dietary fiber intake before surgery was associated with a lower risk of any postoperative complications and surgical postoperative complications. Among patients with an anastomosis, dietary fiber intake was not associated with risk of anastomotic leakage.

Meaning The findings suggest that improving preoperative dietary fiber intake may be considered as a strategy in future prehabilitation programs for patients undergoing surgery for colorectal cancer.

proved by the Committee on Research Involving Human Subjects, Arnhem-Nijmegen, the Netherlands. This study followed the Strengthening the Reporting of Observational Studies in Epidemiology (STROBE) reporting guideline.

We included 1641 patients recruited between August 2010 and December 2017 and for whom linkage with the clinical databases was completed at the time of analysis (Figure 1). Patients with stage 0 disease $(n=3)$ and those who did not undergo surgery $(n=12)$ were excluded. Patients who underwent nonelective $(n=15)$ or transanal $(n=13)$ surgery or received hyperthermic intraperitoneal chemotherapy $(n=4)$ and those with missing data on fiber intake $(n=125)$ were excluded. In addition, patients with missing outcome data ( $\mathrm{n}=70$ for any complications, $\mathrm{n}=12$ for surgical complications, and $\mathrm{n}=13$ for anastomotic leakage) were excluded, resulting in a study population of 1399 patients.

\section{Dietary Fiber Intake}

Data on habitual dietary intake during the 1 month before diagnosis were collected via a self-administered and semiquantitative 204-item food frequency questionnaire (FFQ) completed shortly after diagnosis. ${ }^{28,29}$ Total dietary fiber intake was calculated based on the frequency of intake, number of portions, and standard portion sizes of relevant items using data from the 2011 Dutch food composition tables. ${ }^{30}$ To further explore different fiber sources, intake of fiber from fruits, vegetables, cereals, whole grains, and refined grains was analyzed separately because these were the major fiber sources in this population.

\section{Clinical Outcomes}

Disease characteristics and clinical outcome data were obtained from the Dutch Colorectal Audit, ${ }^{31}$ which reports the occurrence of postoperative complications within 30 days after surgery. Clinical outcomes considered for this study were any or surgical postoperative complications and anastomotic leakage. Any complications included surgical postoperative complications and other (eg, pulmonary, neurological, or cardiovascular) postoperative complications. Surgical complications included surgical site infection, anastomotic leakage, or postoperative ileus, among others. Anastomotic leakage was only 
Figure 1. Flow Diagram of Patients With Colorectal Cancer Who Underwent Elective Abdominal Tumor Resection

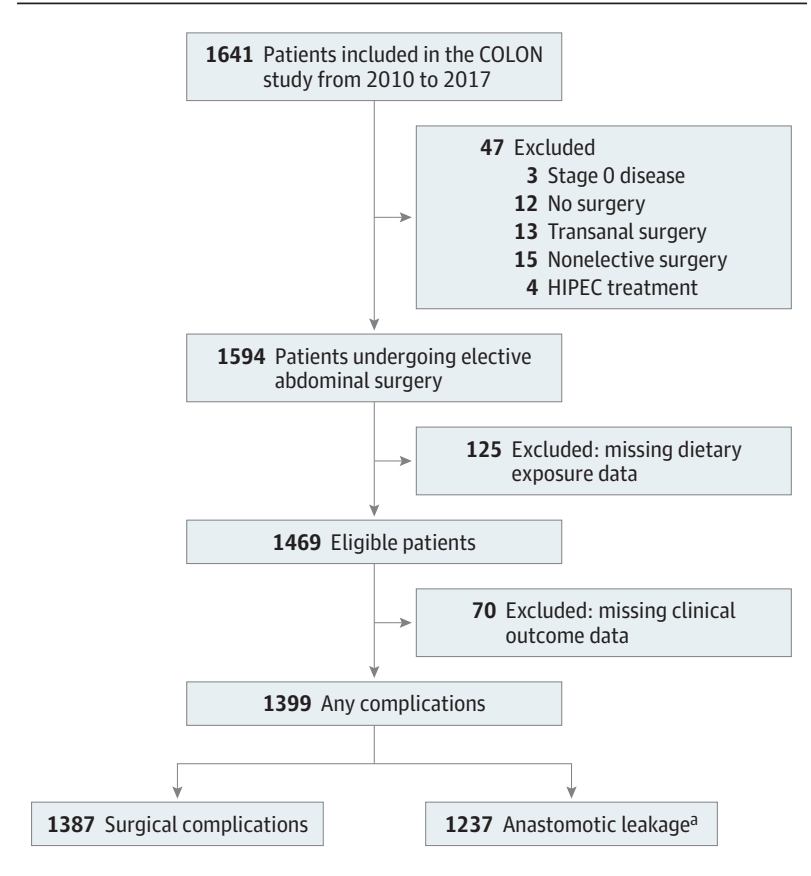

COLON indicates Colorectal Longitudinal, Observational Study on Nutritional and Lifestyle Factors study; HIPEC, hyperthermic intraperitoneal chemotherapy. a $\mathrm{Of} 1250$ patients with anastomosis.

considered in patients with an anastomosis $(n=1250)$. Anastomotic leakage was defined as an anastomotic leak that required a reintervention within 30 days after the surgical procedure. Tumor stage, physical status classification of the American Association of Anesthesiologists (ASA), surgical procedures, and other treatment characteristics were also obtained from the Dutch Colorectal Audit.

\section{Descriptive Data and Covariates}

Additional information on general and lifestyle factors was obtained through questionnaires completed at the time of diagnosis. Body mass index was calculated based on selfreported weight and height. Smoking status was defined as current, former, or never. The validated Short Questionnaire to Assess Health-enhancing Physical Activity (SQUASH) was used to assess time spent doing moderate to vigorous physical activity, as described elsewhere. ${ }^{32,33}$

\section{Statistical Analysis}

Data were analyzed between December 2019 and September 2020. Patients' characteristics are presented as descriptive data using medians and interquartile ranges (IQRs) or numbers and percentages. The association between fiber intake and risk of postoperative complications was assessed using logistic regression analyses. Total dietary fiber intake was considered continuously (per $10 \mathrm{~g}$ per day) and in tertiles, with the lowest tertile (T1) being the reference category. For dietary fiber intake from individual fiber sources, intake was considered per $1 \mathrm{~g}$ per day because intake from these sources is lower than total dietary fiber intake. $P$ values for trends were calculated by including median fiber intake for each tertile as an independent continuous variable in the model, with $P<.05$ indicating statistical significance. Crude analyses were adjusted for age and sex. To consider potential confounding, analyses were further adjusted for smoking status (former, current, or never), ASA classification (I, II, or III-IV), and tumor location (colon, rectum) because these variables are known to be associated with postoperative complications in patients with $\mathrm{CRC}^{13,34,35}$ or with dietary fiber intake ${ }^{36,37}$ or were used as covariates in previous studies. ${ }^{38,39}$ Other potential confounders, such as body mass index, tumor stage (I, II, III, or IV), physical activity (minutes per week), and energy intake (kcal per day) were added one by one to the models. When one of these variables changed the effect estimate by more than $10 \%$, the variable was included in the model as a covariate.

Stratified analyses were performed for sex because previous studies ${ }^{40,41}$ suggested that effects of fiber on microbiota composition, SCFA production, and immune parameters, at least in rodent models, may be sex specific. Stratified analyses for tumor location (colon vs rectum) were performed because it was hypothesized that associations between fiber intake and postoperative complications may differ owing to pronounced differences in microbiota composition and molecular tumor features in these locations. ${ }^{42,43}$ In stratified analyses, results are presented per $10-\mathrm{g} / \mathrm{d}$ increase in dietary fiber intake and not per tertile of dietary fiber intake because the number of patients per group would be insufficiently small. $P$ values for interaction were calculated by adding product terms for dietary fiber intake $\times$ sex or dietary fiber intake $\times$ tumor location to the main models, with adjustment for the aforementioned confounders.

Sensitivity analyses were performed excluding patients with stage IV cancer or an unknown stage of cancer $(n=87)$ because the risk of complications might be predominantly associated with compromised health rather than dietary aspects among these patients. We primarily focused on absolute fiber intake because the actual amount of fiber passing through the gastrointestinal tract might be most important from a biological point of view. To study intake of fiber relative to energy intake, sensitivity analyses were performed using energy-adjusted fiber intake as the exposure variable. The residual method was used to calculate energy-adjusted fiber intake, ${ }^{44}$ and energy intake (in kcal per day) was added to the previously mentioned covariates in the models. We also excluded patients who completed the FFQ more than 30 days before or less than 14 days after surgery for CRC or with a missing FFQ completion date $(n=280)$. Finally, to explore whether a stoma or neoadjuvant treatment (chemotherapy and/or radiotherapy) affected the associations, sensitivity analyses excluding patients with a stoma created during surgery $(n=419)$ or who received neoadjuvant treatment $(n=335)$ were performed. Stratified and sensitivity analyses were performed for any postoperative complications as the outcome because the number of patients in the subgroups would be insufficiently small for the other outcomes. All analyses were performed using SPSS, version 25 (IBM Corp). A 2-sided $P<.05$ was considered statistically significant. 


\section{Results}

In total, 1399 patients were included in this study (Figure 1). The median time between completion of the FFQ and surgery was 8 days (IQR, 2-17 days). The median age of the patients was 66 years (IQR, 61-72 years), 896 (64\%) were men, and most had a diagnosis of colon cancer (956 [68\%]) vs rectal cancer (443 [32\%]) (Table 1). Median habitual fiber intake was $19.6 \mathrm{~g} / \mathrm{d}$ (IQR, 15.8-24.2 g/d), and 125 patients (9\%) adhered to the national recommendation for dietary fiber intake $(\geq 3.4 \mathrm{~g} / \mathrm{MJ}) .{ }^{45}$ Any postoperative complications were registered for 397 patients (28\%), with surgical complications occurring in 235 patients (17\%) and anastomotic leaks in 67 of 1237 patients with an anastomosis (5\%).

Compared with the patients who did not have complications within 30 days after the surgical procedure $(n=1002)$, patients who experienced any complications $(n=397)$ more often were men (279 [70\%] vs 617 [62\%]), reported current smoking (63 [16\%] vs 88 [9\%]), had a diagnosis of rectal cancer (172 [43\%] vs 271 [27\%]), had received neoadjuvant treatment (134 [34\%] vs 201 [20\%]), and had an ASA classification of III or IV (75 [19\%] vs 89 [9\%]). Patients with complications also more often received a stoma during surgery (170 [44\%] vs 229 [23\%]), were more often admitted to the intensive care unit (88 [23\%] vs 17 [2\%]), and had a longer hospital length of stay (median, 11 days [IQR, 7-18 days] vs 5 days [IQR, 4-7 days]) (Table 1).

Compared with patients with the lowest fiber intake (T1) ( $n=466)$, patients with the highest fiber intake (T3) $(n=466)$ were more often men (326 [70\%] vs 272 [58\%]), less often reported current smoking (40 [9\%] vs 66 [14\%]), had higher energy intake (median, $2222 \mathrm{kcal} / \mathrm{d}$ [IQR, 1966-2580 kcal/d] vs $1439 \mathrm{kcal} / \mathrm{d}$ [IQR, 1235-1655 kcal/d]), and were more physically active (median, 870 minutes/week [IQR, 480-1418 minutes/week] vs 450 minutes/week [IQR, 240-888 minutes/ week]). Patients with the highest fiber intake also had lower rates of any postoperative complications (117 [25\%] vs 151 [32\%]) (eTable in the Supplement).

In adjusted logistic regression analyses, higher dietary fiber intake (per $10 \mathrm{~g} / \mathrm{d}$ ) was significantly associated with a lower risk of any complications (odds ratio [OR], 0.75; 95\% CI, 0.62-0.92) and surgical complications (OR, 0.76; 95\% CI, 0.60-0.97). For patients with an anastomosis, intake of fiber was not associated with occurrence of anastomotic leakage (OR, 0.97; 95\% CI, 0.66-1.43) (Table 2).

In stratified analyses, higher dietary fiber intake was associated with a lower risk of any postoperative complications in women (OR, 0.64; 95\% CI, 0.44-0.94), whereas there was no association for men (OR, 0.79; 95\% CI, 0.63-1.01) ( $P=.28$ for interaction), although the risk estimates pointed in the same direction and the difference between men and women was relatively small. In stratified analyses for tumor location, dietary fiber intake was not associated with risk of any complications in patients with colon cancer (OR, 0.78; 95\% CI, 0.61-1.01), but there was an association between dietary fiber intake and risk of any complications in patients with rectal cancer (OR, 0.71; 95\% CI, 0.51-0.98) ( $P=.89$ for interaction) (Table 3).
In sensitivity analyses, exclusion of patients with stage IV or unknown cancer stage $(n=87)$, patients with a stoma or with unknown stoma status $(n=419)$, patients who completed the FFQ more than 30 days before or less than 14 days after surgery or with unknown completion date $(n=280)$, and patients who received neoadjuvant treatment $(n=335)$ did not substantially change results compared with the main analyses. Considering energy-adjusted fiber intake in sensitivity analyses did not substantially change effect estimates compared with the main analyses, although there were no longer significant associations between higher fiber intake and any (OR, 0.76; 95\% CI, 0.57-1.02) and surgical (OR, 0.73; 95\% CI, 0.51-1.03) postoperative complications.

To further explore the potential relevance of the different sources of fiber, we also conducted the main analyses with intake of dietary fiber (now per 1-g/d increase) specified for the main sources of dietary fiber in this population (fiber from cereals, refined grains, whole grains, fruits, and vegetables). Among the fiber sources, the associations with intake of fiber from vegetables were strongest; for any complications, the OR was 0.90 (95\% CI, 0.83-0.99) and for surgical complications, the OR was 0.87 (95\% CI, 0.78-0.97) (Figure 2).

\section{Discussion}

To our knowledge, this is the first study showing that higher habitual dietary fiber intake before surgery was associated with a lower risk of any or surgical postoperative complications in patients with CRC. Dietary fiber intake was not associated with risk of anastomotic leakage among patients with anastomosis. Higher dietary fiber intake was associated with a lower risk of any postoperative complications among women but not among men, although the difference in risk estimates between men and women was relatively small. Fiber from vegetables was inversely associated with any complications or surgical complications.

The literature on the association between habitual and preoperative dietary fiber intake and postoperative outcomes is scarce. Berstad et al ${ }^{46}$ compared patients with CRC with $(\mathrm{n}=29$ ) and without $(\mathrm{n}=71)$ postoperative complications and did not observe a difference in daily fiber intake ( $2.7 \mathrm{~g} / \mathrm{MJ}$ vs $2.8 \mathrm{~g} / \mathrm{MJ})$ or the proportion of patients who adhered to the recommendation for fiber intake ( $\geq 3 \mathrm{~g} / \mathrm{MJ}$ ) (35\% vs $31 \%)$. However, that study was based on a relatively small population, and analyses were not adjusted for relevant confounding factors. Moreover, adherence to recommendations for fiber intake was high compared with that in the population in the present study. Similar to the US and several other European countries, ${ }^{20,47,48}$ fiber intake is relatively low in the Netherlands (median, 20.8 g/d among adults), ${ }^{49}$ which was reflected by only $9 \%$ of patients in the present study adhering to national recommendations.

The mechanisms by which fiber intake might be associated with postoperative complications are unclear, although the classical role of fiber in maintaining gut health is considered plausible. ${ }^{50}$ The intestinal microbiota reflects an aspect of gut health that has been suggested to impact postoperative 


\begin{tabular}{|c|c|c|c|}
\hline \multirow[b]{3}{*}{ Characteristic } & \multicolumn{3}{|l|}{ Patients $^{\mathrm{a}}$} \\
\hline & \multirow[b]{2}{*}{ Overall $(N=1399)$} & \multicolumn{2}{|c|}{ Any postoperative complication $(n=1399)$} \\
\hline & & Yes $(n=397[28 \%])$ & No $(n=1002[72 \%])$ \\
\hline Age, median (IQR), y & $66(61-72)$ & $67(62-73)$ & $66(61-71)$ \\
\hline \multicolumn{4}{|l|}{ Sex } \\
\hline Male & $896(64)$ & $279(70)$ & $617(62)$ \\
\hline Female & $503(36)$ & $118(30)$ & $385(38)$ \\
\hline BMI, median (IQR) ${ }^{\mathrm{b}}$ & $26.0(24.0-28.7)$ & $26.5(24.0-29.1)$ & $25.9(23.9-28.7)$ \\
\hline \multicolumn{4}{|l|}{ Smoking } \\
\hline Current & $151(11)$ & $63(16)$ & $88(9)$ \\
\hline Former & $818(59)$ & $220(56)$ & $598(60)$ \\
\hline Never & $424(30)$ & $113(29)$ & $311(31)$ \\
\hline Unknown & $6(0.4)$ & $1(0.2)$ & $5(0.5)$ \\
\hline $\begin{array}{l}\text { Adhered to recommendation for dietary } \\
\text { fiber intake }{ }^{c}\end{array}$ & $125(9)$ & $34(9)$ & $91(9)$ \\
\hline \multicolumn{4}{|l|}{ Dietary fiber intake, median (IQR), g/d } \\
\hline Total dietary fiber & $19.6(15.8-24.2)$ & $18.8(15.2-23.2)$ & $20.1(16.1-24.5)$ \\
\hline Cereal fiber & $8.9(6.7-11.3)$ & $8.6(6.4-10.9)$ & $9.1(6.8-11.5)$ \\
\hline Whole grain fiber & $6.8(4.7-9.0)$ & $6.5(4.4-8.8)$ & $6.9(4.8-9.1)$ \\
\hline Refined grain fiber & $1.8(1.0-3.0)$ & $1.7(1.0-2.8)$ & $1.9(1.1-3.0)$ \\
\hline Fruit fiber & $2.6(1.3-3.9)$ & $2.1(1.2-3.8)$ & $2.7(1.3-4.0)$ \\
\hline Vegetable fiber & $2.3(1.4-3.3)$ & $2.1(1.2-3.0)$ & $2.4(1.5-3.4)$ \\
\hline Energy intake, median (IQR), kcal/d & $1819(1503-2169)$ & $1791(1470-2143)$ & $1822(1508-2185)$ \\
\hline $\begin{array}{l}\text { Moderate to vigorous physical activity, } \\
\text { median (IQR), } \mathrm{min} / \mathrm{wk}^{\mathrm{d}}\end{array}$ & $660(330-1140)$ & $600(300-1100)$ & $690(330-1170)$ \\
\hline \multicolumn{4}{|l|}{ Tumor location ${ }^{\mathrm{e}}$} \\
\hline Colon & $956(68)$ & $225(57)$ & $731(73)$ \\
\hline Rectum & $443(32)$ & $172(43)$ & $271(27)$ \\
\hline \multicolumn{4}{|l|}{ Tumor stage } \\
\hline 1 & $345(25)$ & $83(21)$ & $262(26)$ \\
\hline II & $381(27)$ & $113(29)$ & $268(27)$ \\
\hline III & $586(42)$ & $179(45)$ & $407(41)$ \\
\hline IV & $79(6)$ & $21(5)$ & $58(6)$ \\
\hline Unknown & 8 & 1 & 7 \\
\hline $\begin{array}{l}\text { Received neoadjuvant radiotherapy } \\
\text { and/or chemotherapy }\end{array}$ & $335(24)$ & $134(34)$ & $201(20)$ \\
\hline \multicolumn{4}{|l|}{ ASA classification } \\
\hline 1 & $414(30)$ & $83(22)$ & $331(34)$ \\
\hline$\|$ & $793(58)$ & $228(59)$ & $565(57)$ \\
\hline III & $161(12)$ & $73(19)$ & $88(9)$ \\
\hline IV & $3(0.2)$ & $2(0.5)$ & $1(0.1)$ \\
\hline Unknown & 28 & 11 & 17 \\
\hline \multicolumn{4}{|l|}{ Surgical approach } \\
\hline Open & $350(25)$ & $115(30)$ & $235(24)$ \\
\hline Laparoscopic & $1032(75)$ & $274(70)$ & $758(76)$ \\
\hline Unknown & 17 & 8 & 9 \\
\hline Anastomosis $^{f}$ & $1250(90)$ & $342(87)$ & $908(91)$ \\
\hline Stoma ${ }^{g}$ & $399(29)$ & $170(44)$ & $229(23)$ \\
\hline $\begin{array}{l}\text { Admitted to intensive care unit } \\
\text { for at least } 1 \mathrm{~d}^{\mathrm{h}}\end{array}$ & $105(8)$ & $88(23)$ & $17(2)$ \\
\hline Length of hospital stay, median (IQR), di & $6(4-9)$ & $11(7-18)$ & $5(4-7)$ \\
\hline
\end{tabular}

Abbreviations: ASA, American Association of Anesthesiologists; BMI, body mass index (calculated as weight in kilograms divided by height in meters squared); IQR, interquartile range.

a Data are presented as number (percentage) of patients unless otherwise indicated.

${ }^{\mathrm{b}}$ Data were missing for 5 patients.

c The recommendation for dietary fiber intake in the Netherlands according to the Health Council is at least $3.4 \mathrm{~g} / \mathrm{MJ}$ per day, including approximately 30 g per day for women and approximately $40 \mathrm{~g}$ per day for men. ${ }^{45}$

${ }^{\mathrm{d}}$ Data were missing for 2 patients.

e Colon includes the cecum, appendix, ascending colon, hepatic flexure, transverse colon, splenic flexure, descending colon, and sigmoid colon. Rectum includes the rectosigmoid junction and rectum.

${ }^{f}$ Data were missing for 3 patients.

${ }^{\mathrm{g}}$ Refers to both defunctioning stomas and permanent end stomas created during surgery. Data were missing for 20 patients.

${ }^{\mathrm{h}}$ Data were missing for 10 patients. i Data were missing for 285 patients. recovery and risk of complications and might mediate the observed associations for fiber intake. ${ }^{16,24,51-53}$

We observed an association between fiber intake and risk of complications among women but not among men, al- though there was no significant interaction between sex and dietary fiber intake. In rodent models, ${ }^{40,41}$ dietary fiber intake affected microbiota composition, SCFA production, and immune parameters in a sex-specific manner. Several, albeit 


\begin{tabular}{|c|c|c|c|c|c|}
\hline & \multirow{2}{*}{$\begin{array}{l}\text { Dietary fiber } \\
\text { intake, median } \\
\text { (IQR), g/d }\end{array}$} & \multicolumn{2}{|l|}{ Crude model $^{\mathrm{a}}$} & \multicolumn{2}{|l|}{ Adjusted model $^{\mathrm{b}}$} \\
\hline & & $\begin{array}{l}\text { Events, No./ } \\
\text { total population, No. }\end{array}$ & OR $(95 \% \mathrm{Cl})$ & $\begin{array}{l}\text { Events, No./ } \\
\text { total population, No. }\end{array}$ & OR $(95 \% \mathrm{CI})$ \\
\hline \multicolumn{6}{|l|}{ Any complications } \\
\hline $\begin{array}{l}\text { Dietary fiber intake, } \\
\text { per } 10 \mathrm{~g} / \mathrm{d}\end{array}$ & $19.6(15.8-24.2)$ & $397 / 1399$ & $\begin{array}{l}0.74 \\
(0.61-0.89)\end{array}$ & $385 / 1365$ & $\begin{array}{l}0.75 \\
(0.62-0.92)\end{array}$ \\
\hline \multicolumn{6}{|l|}{ Dietary fiber intake } \\
\hline Tertile 1 & $14.4(12.2-15.8)$ & $151 / 466$ & 1 [Reference] & $148 / 457$ & 1 [Reference] \\
\hline Tertile 2 & $19.6(18.4-21.0)$ & $129 / 467$ & $\begin{array}{l}0.78 \\
(0.59-1.03)\end{array}$ & $123 / 452$ & $\begin{array}{l}0.76 \\
(0.56-1.02)\end{array}$ \\
\hline Tertile 3 & $26.1(24.1-29.5)$ & $117 / 466$ & $\begin{array}{l}0.69 \\
(0.52-0.92)\end{array}$ & $114 / 456$ & $\begin{array}{l}0.72 \\
(0.53-0.98)\end{array}$ \\
\hline$P$ value for trend & NA & NA & .01 & NA & .04 \\
\hline \multicolumn{6}{|l|}{ Surgical complications } \\
\hline $\begin{array}{l}\text { Dietary fiber intake, } \\
\text { per } 10 \mathrm{~g} / \mathrm{d}\end{array}$ & $19.7(15.8-24.2)$ & $235 / 1387$ & $\begin{array}{l}0.76 \\
(0.60-0.95)\end{array}$ & $231 / 1354$ & $\begin{array}{l}0.76 \\
(0.60-0.97)\end{array}$ \\
\hline \multicolumn{6}{|l|}{ Dietary fiber intake } \\
\hline Tertile 1 & $14.4(12.2-15.8)$ & $89 / 463$ & 1 [Reference] & $89 / 454$ & 1 [Reference] \\
\hline Tertile 2 & $19.7(18.4-21.0)$ & $81 / 461$ & $\begin{array}{l}0.89 \\
(0.63-1.24)\end{array}$ & $78 / 447$ & $\begin{array}{l}0.85 \\
(0.61-1.20)\end{array}$ \\
\hline Tertile 3 & $26.1(24.2-29.5)$ & $65 / 463$ & $\begin{array}{l}0.68 \\
(0.47-0.96)\end{array}$ & $64 / 453$ & $\begin{array}{l}0.69 \\
(0.48-0.98)\end{array}$ \\
\hline$P$ value for trend & NA & NA & .03 & NA & .04 \\
\hline \multicolumn{6}{|l|}{ Anastomotic leakage ${ }^{c}$} \\
\hline $\begin{array}{l}\text { Dietary fiber intake, } \\
\text { per } 10 \mathrm{~g} / \mathrm{d}\end{array}$ & $19.6(15.7-24.3)$ & $67 / 1237$ & $\begin{array}{l}0.91 \\
(0.62-1.33)\end{array}$ & $65 / 1208$ & $\begin{array}{l}0.97 \\
(0.66-1.43)\end{array}$ \\
\hline \multicolumn{6}{|l|}{ Dietary fiber intake } \\
\hline Tertile 1 & $14.2(11.9-15.7)$ & $23 / 414$ & 1 [Reference] & $23 / 406$ & 1 [Reference] \\
\hline Tertile 2 & $19.6(18.3-21.0)$ & $22 / 410$ & $\begin{array}{l}0.95 \\
(0.52-1.73)\end{array}$ & $20 / 397$ & $\begin{array}{l}0.92 \\
(0.49-1.72)\end{array}$ \\
\hline Tertile 3 & $26.1(24.2-29.5)$ & $22 / 413$ & $\begin{array}{l}0.86 \\
(0.47-1.58)\end{array}$ & $22 / 405$ & $\begin{array}{l}0.95 \\
(0.51-1.77)\end{array}$ \\
\hline$P$ value for trend & NA & NA & .62 & NA & .89 \\
\hline
\end{tabular}

Abbreviations: IQR, interquartile range; NA, not applicable; OR, odds ratio.

a The crude model was adjusted for age (continuous in years) and sex.

b The adjusted model was adjusted for age, sex, smoking status (former, current, or never), American Association of Anesthesiologists classification (I, II, or III-IV), and tumor location (colon, rectum).

${ }^{c}$ Analyses were restricted to patients with an anastomosis.

\begin{tabular}{|c|c|c|c|}
\hline \multirow[b]{2}{*}{ Stratified analysis } & \multirow[b]{2}{*}{$\begin{array}{l}\text { Dietary fiber intake, } \\
\text { median (IQR), g/d }\end{array}$} & \multicolumn{2}{|l|}{ Adjusted model $^{\mathrm{a}}$} \\
\hline & & $\begin{array}{l}\text { Events, No./ } \\
\text { total population, No. }\end{array}$ & OR $(95 \% \mathrm{Cl})$ \\
\hline \multicolumn{4}{|l|}{ Sex } \\
\hline \multicolumn{4}{|c|}{ Dietary fiber intake, per $10 \mathrm{~g} / \mathrm{d}$} \\
\hline Women & $18.8(15.2-22.9)$ & $116 / 497$ & $0.64(0.44-0.94)$ \\
\hline Men & $20.2(16.2-24.8)$ & $269 / 868$ & $0.79(0.63-1.01)$ \\
\hline \multicolumn{4}{|l|}{ Tumor location } \\
\hline \multicolumn{4}{|c|}{ Dietary fiber intake, per $10 \mathrm{~g} / \mathrm{d}$} \\
\hline Colon $^{\mathrm{b}}$ & $19.8(15.8-24.2)$ & $219 / 929$ & $0.78(0.61-1.01)$ \\
\hline Rectum ${ }^{c}$ & $19.4(15.7-23.8)$ & $166 / 436$ & $0.71(0.51-0.98)$ \\
\hline $\begin{array}{l}\text { Abbreviations: IQR, it } \\
\text { a Models were adjust } \\
\text { sex), smoking statu } \\
\text { Anesthesiologists cl } \\
\text { rectum; not in analy }\end{array}$ & $\begin{array}{l}\text { analyses stratified for } \\
\text { erican Association of } \\
\text { mor location (colon, }\end{array}$ & \multicolumn{2}{|c|}{ c Rectum includes the rectosigmoid junction and rectum. } \\
\hline
\end{tabular}

speculative, hypotheses might explain our findings. Higher fiber intake has been associated with a reduction in circulating estrogen concentrations and increased fecal excretion of estrogens in human and animal studies. ${ }^{54-56}$ Dietary fiber can bind estrogens released from the bile in the gastrointestinal tract and thereby can prevent reabsorption through interruption of the enterohepatic circulation. ${ }^{57}$ Although the biological and clinical significance of this phenomenon is unknown, studies have shown that estrogens might promote wound healing and improve perfusion. ${ }^{58-60}$ Another explanation might be that, in general, women tend to consume relatively more fruits and vegetables and fewer cereals or cereal products compared with men. ${ }^{61,62}$ Dietary fiber from these respective sources may differ in terms of solubility, fermentability, or viscosity and, as such, may have different bulking effects, bacterial fermentation, or absorptive capacity in the colon. ${ }^{63,64}$ The observa- 

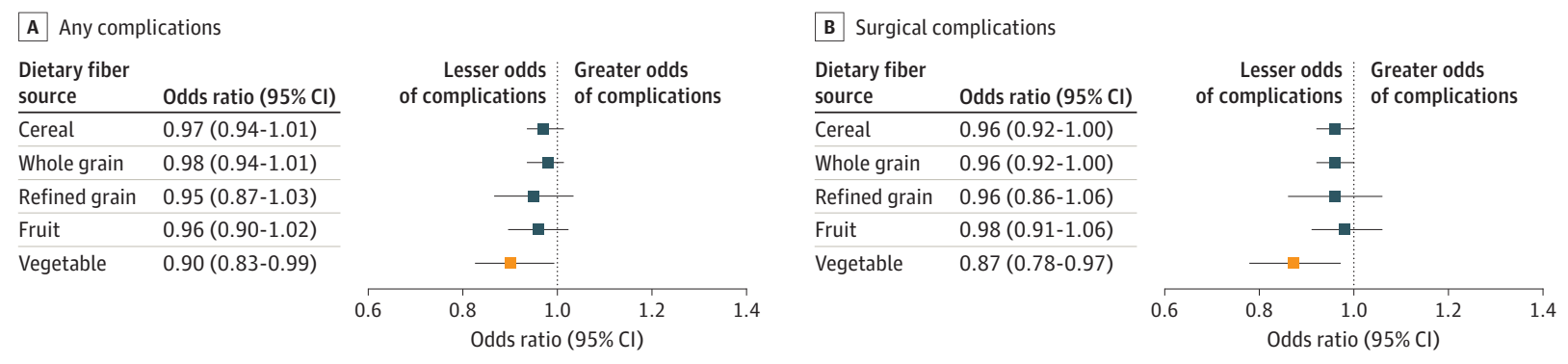

Analyses were adjusted for age, sex, smoking status, American Association of Anesthesiologists classification, and tumor location and were mutually adjusted for dietary fiber intake of other sources. Cereal fiber was further adjusted for fruit fiber and vegetable fiber. Whole grain fiber was further adjusted for refined grain fiber, fruit fiber, and vegetable fiber. Refined grain fiber was further adjusted for whole grain fiber, fruit fiber, and vegetable fiber. Fruit fiber was further adjusted for vegetable fiber, whole grain fiber, and refined grain fiber. Vegetable fiber was further adjusted for fruit fiber, whole grain fiber, and refined grain fiber. Markers indicate odds ratios per $1 \mathrm{~g}$ per day increase in fiber intake, with horizontal lines indicating $95 \% \mathrm{Cls}$.

tion for which we found the strongest associations for fiber from vegetables is supportive of this hypothesis.

We found no significant associations between fiber intake and risk of anastomotic leakage. These findings contradict a previous preclinical study ${ }^{65}$ showing that a high-fiber and low-fat diet resulted in a decreased risk of anastomotic leakage compared with a Western-style diet (low fiber and high fat). Whether effects in this animal study were attributed to dietary fiber, fat, or both is unknown, which together with the Western-style diet lacking dietary fiber ${ }^{65}$ rather than a modest fiber intake seen in human populations, might explain differences with our findings. In addition, the relatively low proportion (5\%) of patients with anastomotic leakage might explain failure to detect an association in our study.

\section{Strengths and Limitations}

Strengths of this study include the prospective design and timing of exposure assessment, which is relevant from a prehabilitation point of view. Moreover, to our knowledge, this was the first study specifically focusing on habitual fiber intake in association with complications after surgical treatment for CRC that considered a comprehensive panel of dietary, other lifestyle, and clinical factors.

Limitations of this study include the modest number of events, especially for surgical complications and anastomotic leakage, which limited statistical power to conduct stratified and sensitivity analyses for these outcomes. In line with this and given the nature of the data, we were not able to differentiate between specific types of surgical complications other than anastomotic leakage. Second, we focused on habitual dietary fiber intake reflecting the 4 weeks before diagnosis. Patients might have changed their dietary habits after diagnosis and before the surgical procedure, although a previous study ${ }^{66}$ on lifestyle changes after diagnosis in this cohort revealed that this was likely not the case. Because the median time between completion of the FFQ and surgery was only
8 days (IQR, 2-17 days), it is not likely that changes in dietary fiber intake substantially impacted our findings. Third, for some patients, data on the exposure (fiber intake, $n=125$ ) or the outcome (complications, $\mathrm{n}=70$ ) were missing. These patients, however, did not differ substantially from the study population in terms of sociodemographic characteristics and cancer stage. In addition, although we carefully considered multiple clinical, nutritional, and other lifestyle factors, we cannot exclude the possibility of residual confounding inherent to the observational design of our study. Of note, energy adjustment using the residual method ${ }^{44}$ resulted in slight attenuation of observed associations in terms of statistical significance, although effect estimates remained similar compared with the main analyses. This phenomenon has also been observed in other studies focusing on dietary fiber. ${ }^{67}$ The wider 95\% CIs calculated after energy adjustment may reflect overadjustment or unnecessary adjustment. ${ }^{67,68}$ From a biological point of view, we consider absolute dietary fiber more relevant than relative intake because the actual amount of fiber passing through the gastrointestinal tract might be more important with regard to biological events. For these reasons, we primarily based our conclusions on the non-energy-adjusted models.

\section{Conclusions}

In this cohort study, higher dietary fiber intake before surgery was associated with a lower risk of any or surgical postoperative complications in patients with CRC. The findings suggest that improving preoperative dietary fiber intake may be considered in future prehabilitation programs for patients undergoing surgery for CRC. Further intervention studies appear to be needed to confirm the feasibility and clinical relevance of increased dietary fiber intake in the time between diagnosis and the surgical procedure.
ARTICLE INFORMATION

Accepted for Publication: March 31, 2021.
Published Online: June 16, 2021

doi:10.1001/jamasurg.2021.2311
Author Contributions: Drs Kok and Kampman had full access to all of the data in the study and take 
responsibility for the integrity of the data and the accuracy of the data analysis.

Concept and design: Kok, Huibregtse, Kruyt, Bac, van Halteren, de Wilt, Kampman.

Acquisition, analysis, or interpretation of data: Kok, Arron, Huibregtse, Kruyt, Kouwenhoven, Wesselink, Winkels, van Zutphen, van Duijnhoven, Kampman.

Drafting of the manuscript: Kok, Arron, Bac van Halteren.

Critical revision of the manuscript for important intellectual content: Arron, Huibregtse, Kruyt, van Halteren, Kouwenhoven, Wesselink, Winkels, van Zutphen, van Duijnhoven, de Wilt, Kampman. Statistical analysis: Kok, Arron, Huibregtse, van Duijnhoven.

Obtained funding: Kok, van Duijnhoven, Kampman. Administrative, technical, or material support:

Kruyt, Bac, Wesselink, van Zutphen.

Supervision: Kruyt, Winkels, de Wilt, Kampman.

Conflict of Interest Disclosures: Mrs van Zutphen reported receiving grants from the Dutch Cancer Society outside the submitted work. Dr de Wilt reported receiving grants from the Dutch Cancer Society, the Netherlands Organisation for Health Research and Development, Roche, and Covidien outside the submitted work. No other disclosures were reported.

Funding/Support: This study was supported by grant 016.Veni.188.082 from the Dutch Research Council (Dr Kok). The Colorectal Longitudinal, Observational Study on Nutritional and Lifestyle Factors (COLON) study was supported by Wereld Kanker Onderzoek Fonds and World Cancer Research Fund International; grant 2014/1179 (Dr Kampman) from the World Cancer Research Fund International Regular Grant Programme; grant UW 2013-5927 (Dr van Duijnhoven) from Alpe d'Huzes/Dutch Cancer Society; grant UW 2015-7946 from the Dutch Cancer Society (Dr van Duijnhoven); grants UW2013-6397 and UW2014-6877 from the ERA-NET on Translational Cancer Research, Dutch Cancer Society (Dr Kampman); and The Netherlands Organisation for Health Research and Development.

Role of the Funder/Sponsor: The funders had no role in the design and conduct of the study: collection, management, analysis, and interpretation of the data; preparation, review, or approval of the manuscript; and decision to submit the manuscript for publication.

Additional Contributions: We thank all participants, the involved coworkers in the participating hospitals, the COLON investigators at Wageningen University \& Research, and all surgeons and other health care professionals who were involved in registering patients in the Dutch Colorectal Audit.

\section{REFERENCES}

1. Brouwer NPM, Bos ACRK, Lemmens VEPP, et al. An overview of 25 years of incidence, treatment and outcome of colorectal cancer patients. Int J Cancer. 2018;143(11):2758-2766. doi:10.1002/ijc. 31785

2. Kirchhoff P, Clavien P-A, Hahnloser D. Complications in colorectal surgery: risk factors and preventive strategies. Patient Saf Surg. 2010;4(1):5. doi:10.1186/1754-9493-4-5

3. Saraste D, Martling A, Nilsson PJ, et al. Complications after colonoscopy and surgery in a population-based colorectal cancer screening programme. J Med Screen. 2016;23(3):135-140. doi:10.1177/0969141315625701

4. Guillou PJ, Quirke $P$, Thorpe $H$, et al; MRC CLASICC trial group. Short-term endpoints of conventional versus laparoscopic-assisted surgery in patients with colorectal cancer (MRC CLASICC trial): multicentre, randomised controlled trial. Lancet. 2005;365(9472):1718-1726. doi:10.1016/SO140-6736 (05)66545-2

5. Tevis SE, Kennedy GD. Postoperative complications: looking forward to a safer future. Clin Colon Rectal Surg. 2016;29(3):246-252. doi:10.1055/s-0036-1584501

6. Snijders HS, Wouters MW, van Leersum NJ, et al. Meta-analysis of the risk for anastomotic leakage, the postoperative mortality caused by leakage in relation to the overall postoperative mortality. Eur $J$ Surg Oncol. 2012;38(11):1013-1019. doi:10.1016/j. ejso.2012.07.111

7. Hammond J, Lim S, Wan Y, Gao X, Patkar A The burden of gastrointestinal anastomotic leaks: an evaluation of clinical and economic outcomes. J Gastrointest Surg. 2014;18(6):1176-1185. doi:10. 1007/s11605-014-2506-4

8. Ashburn JH, Stocchi L, Kiran RP, Dietz DW Remzi FH. Consequences of anastomotic leak after restorative proctectomy for cancer: effect on long-term function and quality of life. Dis Colon Rectum. 2013;56(3):275-280. doi:10.1097/DCR. Ob013e318277e8a5

9. Murphy MM, Tevis SE, Kennedy GD. Independent risk factors for prolonged postoperative ileus development. J Surg Res. 2016 201(2):279-285. doi:10.1016/j.jss.2015.10.047

10. Govaert JA, Fiocco M, van Dijk WA, et al; Dutch Value Based Healthcare Study Group. Costs of complications after colorectal cancer surgery in the Netherlands: building the business case for hospitals. Eur J Surg Oncol. 2015;41(8):1059-1067. doi:10.1016/j.ejso.2015.03.236

11. Vasiliu ECZ, Zarnescu NO, Costea R, Neagu S. Review of risk factors for anastomotic leakage in colorectal surgery. Chirurgia (Bucur). 2015;110(4): 319-326.

12. Sparreboom CL, van Groningen JT, Lingsma HF, et al; Dutch ColoRectal Audit group. Different risk factors for early and late colorectal anastomotic leakage in a nationwide audit. Dis Colon Rectum. 2018;61(11):1258-1266. doi:10.1097/DCR 0000000000001202

13. Bakker IS, Grossmann I, Henneman D, Havenga K, Wiggers T. Risk factors for anastomotic leakage and leak-related mortality after colonic cancer surgery in a nationwide audit. Br J Surg. 2014;101(4):424-432. doi:10.1002/bjs.9395

14. Longo WE, Virgo KS, Johnson FE, et al. Risk factors for morbidity and mortality after colectomy for colon cancer. Dis Colon Rectum. 2000;43(1): 83-91. doi:10.1007/BF02237249

15. Xu Z, Qu H, Kanani G, Guo Z, Ren Y, Chen X. Update on risk factors of surgical site infection in colorectal cancer: a systematic review and meta-analysis. Int J Colorectal Dis. 2020;35(12): 2147-2156. doi:10.1007/s00384-020-03706-8.

16. Stavrou G, Kotzampassi K. Gut microbiome, surgical complications and probiotics. Ann Gastroenterol. 2017;30(1):45-53. doi:10.20524/aog. 2016.0086
17. Schietroma M, Pessia B, Colozzi S, et al. Septic complications after resection for middle or low rectal cancer: role of gut barrier function and inflammatory serum markers. Dig Surg. 2017;34(6): 507-517. doi:10.1159/000475847

18. Burkitt DP, Walker ARP, Painter NS. Effect of dietary fibre on stools and the transit-times, and its role in the causation of disease. Lancet. 1972;2 (7792):1408-1412. doi:10.1016/S0140-6736(72) 92974-1

19. Makki K, Deehan EC, Walter J, Bäckhed F. The impact of dietary fiber on gut microbiota in host health and disease. Cell Host Microbe. 2018;23 (6):705-715. doi:10.1016/j.chom.2018.05.012

20. Stephen AM, Champ MMJ, Cloran SJ, et al. Dietary fibre in Europe: current state of knowledge on definitions, sources, recommendations, intakes and relationships to health. Nutr Res Rev. 2017;30 (2):149-190. doi:10.1017/S095442241700004X

21. Koh A, De Vadder F, Kovatcheva-Datchary P, Bäckhed $F$. From dietary fiber to host physiology: short-chain fatty acids as key bacterial metabolites. Cell. 2016;165(6):1332-1345. doi:10.1016/j.cell.2016. 05.041

22. Desai MS, Seekatz AM, Koropatkin NM, et al. A dietary fiber-deprived gut microbiota degrades the colonic mucus barrier and enhances pathogen susceptibility. Cell. 2016;167(5):1339-1353.e21. doi:10.1016/j.cell.2016.10.043

23. Birchenough G, Schroeder BO, Bäckhed F, Hansson GC. Dietary destabilisation of the balance between the microbiota and the colonic mucus barrier. Gut Microbes. 2019;10(2):246-250. doi:10. 1080/19490976.2018.1513765

24. Alverdy JC, Hyoju SK, Weigerinck M, Gilbert JA The gut microbiome and the mechanism of surgical infection. Br J Surg. 2017;104(2):e14-e23. doi:10. 1002/bjs.10405

25. van Rooijen S, Carli F, Dalton S, et al. Multimodal prehabilitation in colorectal cancer patients to improve functional capacity and reduce postoperative complications: the first international randomized controlled trial for multimodal prehabilitation. BMC Cancer. 2019;19(1):98. doi:10. 1186/s12885-018-5232-6

26. Gillis C, Buhler K, Bresee L, et al. Effects of nutritional prehabilitation, with and without exercise, on outcomes of patients who undergo colorectal surgery: a systematic review and meta-analysis. Gastroenterology. 2018;155(2): 391-410.e4. doi:10.1053/j.gastro.2018.05.012

27. Winkels RM, Heine-Bröring RC, van Zutphen $M$, et al. The COLON study: Colorectal Cancer: Longitudinal, Observational Study on Nutritional and Lifestyle Factors that may influence colorectal tumour recurrence, survival and quality of life. BMC Cancer. 2014;14:374. doi:10.1186/1471-2407-14-374

28. Feunekes IJ, Van Staveren WA, Graveland F, De Vos J, Burema J. Reproducibility of a semiquantitative food frequency questionnaire to assess the intake of fats and cholesterol in The Netherlands. Int J Food Sci Nutr. 1995;46(2):117-123. doi:10.3109/09637489509012539

29. Verkleij-Hagoort AC, de Vries JH, Stegers MP. Lindemans J, Ursem NT, Steegers-Theunissen RP. Validation of the assessment of folate and vitamin B12 intake in women of reproductive age: the method of triads. Eur J Clin Nutr. 2007;61(5):610-615 doi:10.1038/sj.ejcn.1602581 
30. Dutch Nutrition Center. Nederlands voedingsstoffenbestand (NEVO). Bilthoven, the Netherlands: Rijksinstituut voor Volksgezondheid en Milieu; 2011. Accessed August 7, 2020. http://nevo-online.rivm.nl/ 31. Van Leersum NJ, Snijders HS, Henneman D, et al; Dutch Surgical Colorectal Cancer Audit Group. The Dutch Surgical Colorectal Audit. Eur J Surg Oncol. 2013;39(10):1063-1070. doi:10.1016/j.ejso.2013. 05.008

32. Wendel-Vos GC, Schuit AJ, Saris WH, Kromhout D. Reproducibility and relative validity of the Short Questionnaire to Assess Health-enhancing Physical Activity. J Clin Epidemiol. 2003;56(12): 1163-1169. doi:10.1016/S0895-4356(03)00220-8

33. Ainsworth BE, Haskell WL, Herrmann SD, et al. 2011 Compendium of physical activities: a second update of codes and MET values. Med Sci Sports Exerc. 2011;43(8):1575-1581. doi:10.1249/MSS. Ob013e31821ece12

34. Nasser $H$, Ivanics $T$, Leonard-Murali $S$, Stefanou A. Risk Factors for surgical site infection after laparoscopic colectomy: an NSQIP database analysis. J Surg Res. 2020;249:25-33. doi:10.1016/j. jss.2019.12.021

35. Sørensen LT, Jørgensen T, Kirkeby LT, Skovdal J, Vennits B, Wille-Jørgensen P. Smoking and alcohol abuse are major risk factors for anastomotic leakage in colorectal surgery. Br J Surg. 1999;86(7):927-931. doi:10.1046/j.1365-2168.1999.01165.x

36. Wang L, Lo CH, He X, et al. Risk factor profiles differ for cancers of different regions of the colorectum. Gastroenterology. 2020;159(1): 241-256.e13. doi:10.1053/j.gastro.2020.03.054

37. Subar AF, Harlan LC, Mattson ME. Food and nutrient intake differences between smokers and non-smokers in the US. Am J Public Health. 1990; 80(11):1323-1329. doi:10.2105/AJPH.80.11.1323

38. Nickelsen $T N$, Jørgensen $T$, Kronborg $O$. Lifestyle and 30-day complications to surgery for colorectal cancer. Acta Oncol. 2005;44(3):218-223. doi:10.1080/02841860510029707

39. Margadant CC, Bruns ERJ, Sloothaak DAM, et al. Lower muscle density is associated with major postoperative complications in older patients after surgery for colorectal cancer. Eur J Surg Oncol. 2016;42(11):1654-1659. doi:10.1016/j.ejso.2016 05.040

40. Shastri P, McCarville J, Kalmokoff M, Brooks SP, Green-Johnson JM. Sex differences in gut fermentation and immune parameters in rats fed an oligofructose-supplemented diet. Biol Sex Differ. 2015;6:13. doi:10.1186/s13293-015-0031-0

41. Vemuri R, Sylvia KE, Klein SL, et al The microgenderome revealed: sex differences in bidirectional interactions between the microbiota, hormones, immunity and disease susceptibility. Semin Immunopathol. 2019;41(2):265-275. doi:10 1007/s00281-018-0716-7

42. Kim K, Castro EJT, Shim H, Advincula JVG, Kim Y-W. Differences regarding the molecular features and gut microbiota between right and left colon cancer. Ann Coloproctol. 2018;34(6):280-285 doi:10.3393/ac.2018.12.17

43. Youssef O, Lahti L, Kokkola A, et al. Stool microbiota composition differs in patients with stomach, colon, and rectal neoplasms. Dig Dis Sci. 2018;63(11):2950-2958. doi:10.1007/s10620-0185190-5

44. Willett WC, Howe GR, Kushi LH. Adjustment for total energy intake in epidemiologic studies. Am J Clin Nutr. 1997;65(4)(suppl):1220S-1228S. doi:10.1093/ajcn/65.4.1220S

45. Health Council of the Netherlands. Guideline for Dietary Fiber Intake. Health Council of the Netherlands, 2006. Publication No. 2006/03. Accessed August 7, 2020. https://www. gezondheidsraad.nl/documenten/adviezen/2006/ 03/21/richtlijn-voor-de-vezelconsumptie

46. Berstad P, Haugum B, Helgeland M, Bukholm I, Almendingen $\mathrm{K}$. Preoperative body size and composition, habitual diet, and post-operative complications in elective colorectal cancer patients in Norway. J Hum Nutr Diet. 2013;26(4):359-368. doi:10.1111/jhn.12002

47. Mertens E, Kuijsten A, Dofková M, et al. Geographic and socioeconomic diversity of food and nutrient intakes: a comparison of four European countries. Eur J Nutr. 2019;58(4): 1475-1493. doi:10.1007/s00394-018-1673-6 48. McGill CR, Fulgoni VL III, Devareddy L. Ten-year trends in fiber and whole grain intakes and food sources for the United States population: National Health and Nutrition Examination Survey 2001-2010. Nutrients. 2015;7(2):1119-1130. doi:10. 3390/nu7021119

49. van Rossum CTM, Fransen HP, Verkaik-Kloosterman J, Buurma-Rethans EJM, Ocké MC. Dutch National Food Consumption Survey 2007-2010: Diet of Children and Adults Aged 7 to 69 Years. RIVM, National Institute for Public Health and the Environment; 2011. Report No. 350050006. Accessed September 10, 2020. https://www.rivm. nl/bibliotheek/rapporten/350050006.pdf

50. Peredo-Lovillo A, Romero-Luna HE, Jiménez-Fernández M. Health promoting microbial metabolites produced by gut microbiota after prebiotics metabolism. Food Res Int. 2020;136: 109473. doi:10.1016/j.foodres.2020.109473

51. Bachmann R, Leonard D, Delzenne $N$ Kartheuser A, Cani PD. Novel insight into the role of microbiota in colorectal surgery. Gut. 2017;66(4): 738-749. doi:10.1136/gutjnl-2016-312569

52. Lederer AK, Pisarski P, Kousoulas $L$, Fichtner-Feigl S, Hess C, Huber R. Postoperative changes of the microbiome: are surgical complications related to the gut flora? a systematic review. BMC Surg. 2017;17(1):125. doi:10.1186/ s12893-017-0325-8

53. Gaines S, Shao C, Hyman N, Alverdy JC. Gut microbiome influences on anastomotic leak and recurrence rates following colorectal cancer surgery. Br J Surg. 2018;105(2):e131-e141. doi:10. 1002/bjs.10760

54. Rock CL, Flatt SW, Thomson CA, et al. Effects of a high-fiber, low-fat diet intervention on serum concentrations of reproductive steroid hormones in women with a history of breast cancer. J Clin Oncol. 2004;22(12):2379-2387. doi:10.1200/JCO.2004. 09.025

55. Kendall ME, Cohen LA. Effect of dietary fiber on mammary tumorigenesis, estrogen metabolism, and lipid excretion in female rats. In Vivo. 1992;6(3): 239-245.

56. Rose DP, Lubin M, Connolly JM. Effects of diet supplementation with wheat bran on serum estrogen levels in the follicular and luteal phases of the menstrual cycle. Nutrition. 1997;13(6):535-539. doi:10.1016/S0899-9007(97)00032-4

57. Arts CJM, Govers CARL, van den Berg $H$, Wolters MGE, van Leeuwen P, Thijssen JHH. In vitro binding of estrogens by dietary fiber and the in vivo apparent digestibility tested in pigs. J Steroid Biochem Mol Biol. 1991;38(5):621-628. doi:10.1016/ 0960-0760(91)90321-U

58. Emmerson E, Hardman MJ. The role of estrogen deficiency in skin ageing and wound healing. Biogerontology. 2012;13(1):3-20. doi:10. 1007/s10522-011-9322-y

59. Kuebler JF, Jarrar D, Toth B, et al. Estradiol administration improves splanchnic perfusion following trauma-hemorrhage and sepsis. Arch Surg. 2002;137(1):74-79. doi:10.1001/archsurg.137.1.74

60. Brufani M, Rizzi N, Meda C, et al. Novel locally active estrogens accelerate cutaneous wound healing-part 2. Sci Rep. 2017;7(1):2510. doi:10. 1038/s41598-017-02820-y

61. van de Vijver LPL, van den Bosch LMC, van den Brandt PA, Goldbohm RA. Whole-grain consumption, dietary fibre intake and body mass index in the Netherlands cohort study. Eur J Clin Nutr 2009;63(1):31-38. doi:10.1038/sj.ejcn.1602895

62. van Bussel LM, van Rossum CT, Temme EH, Boon PE, Ocké MC. Educational differences in healthy, environmentally sustainable and safe food consumption among adults in the Netherlands. Public Health Nutr. 2020;23(12):2057-2067. doi:10. 1017/S1368980019005214

63. Davison KM, Temple NJ. Cereal fiber, fruit fiber, and type 2 diabetes: explaining the paradox. J Diabetes Complications. 2018;32(2):240-245. doi:10.1016/j.jdiacomp.2017.11.002

64. Dhingra D, Michael M, Rajput H, Patil RT. Dietary fibre in foods: a review. J Food Sci Technol. 2012;49(3):255-266. doi:10.1007/s13197-011-0365-5

65. Hyoju SK, Adriaansens C, Wienholts K, et al. Low-fat/high-fibre diet prehabilitation improves anastomotic healing via the microbiome: an experimental model. Br J Surg. 2019;107(6):743-755 doi:10.1002/bjs.11388

66. van Zutphen M, Boshuizen HC, Kok DE, et al Colorectal cancer survivors only marginally change their overall lifestyle in the first 2 years following diagnosis. J Cancer Surviv. 2019;13(6):956-967. doi:10.1007/s11764-019-00812-7

67. Belle FN, Kampman E, McTiernan A, et al. Dietary fiber, carbohydrates, glycemic index, and glycemic load in relation to breast cancer prognosis in the HEAL cohort. Cancer Epidemiol Biomarkers Prev. 2011;20(5):890-899. doi:10.1158/1055-9965. EPI-10-1278

68. VanderWeele TJ. On the relative nature of overadjustment and unnecessary adjustment. Epidemiology. 2009;20(4):496-499. doi:10.1097/ EDE.0b013e3181a82f12 